\title{
Therapeutics
}

\section{Wearing elastic compression stockings during long-haul flights prevented the development of deep venous thrombosis}

Scurr JH, Machin SJ, Bailey-King S, et al. Frequency and prevention of symptomless deep-vein thrombosis in long-haul flights: a randomised trial. Lancet 2001 May 12;357:1485-9.

QUESTION: In passengers on long-haul flights, does wearing class-I elastic compression stockings while flying prevent the development of deep venous thrombosis (DVT)?

\section{Design}

Randomised (unclear allocation concealment*), blinded (outcome assessor), ${ }^{*}$ controlled trial with 48 hours of follow up.

\section{Setting}

Stamford Hospital, London, UK.

\section{Patients}

231 people who were 56 to 68 years of age (mean age $62 \mathrm{y}, 61 \%$ women) and who intended to travel economy class with 2 sectors of $\geqslant 8$ hours' duration within 6 weeks of enrollment (median flying time $24 \mathrm{~h}$ [interquartile range 19 to $35 \mathrm{~h}$ ] for stocking group, $22 \mathrm{~h}$ [interquartile range 18 to $36 \mathrm{~h}$ ] for control group). Exclusion criteria were episodes of venous thrombosis, use of anticoagulants, regular use of compression stockings, cardiorespiratory problems, or any other serious illness. $87 \%$ of people completed the study and were included in the analysis.

\section{Intervention}

People were allocated to class-I (German Hohenstein compression standard; 20 to $30 \mathrm{~mm} \mathrm{Hg}$ ) below-knee elastic compression stockings $(\mathrm{n}=115)$ or no stockings $(n=116)$. People were advised to put on the stockings before departure and to remove the stockings after arrival for every flight they took.

\section{Main outcome measure}

Presence of DVT confirmed by duplex ultrasonography.

\section{Main results}

Analysis was by intention to treat. At 48 hours after flight travel, no people in the stocking group had symptomless DVT, whereas 12 people in the control group did $(\mathrm{p}<0.001) \dagger$ (table). 4 people in the stocking group had superficial thrombophlebitis, whereas no people in the control group $\operatorname{did}(\mathrm{p}=0.04) \dagger$ (table).

\section{Conclusion}

In passengers on long-haul flights, wearing class-I elastic compression stockings while flying prevented the development of symptomless deep venous thrombosis but increased the risk for superficial thrombophlebitis.

*See glossary.

tp Values calculated from data in article.

\section{COMMENTARY}

For years, it has been assumed that taking long aeroplane trips were associated with an increased risk for DVT-the so-called economy class syndrome. However, despite this assumption, few hard data exist to quantitate the risk. One surprising finding in the study by Scurr $e t$ al was the high incidence of asymptomatic thrombosis in the control group: $10 \%$. Given the decreased sensitivity of ultrasonography for calf vein thrombosis, this finding may be an underestimate. This rate of thrombosis approaches that for general surgery patients. However, all the thrombi were asymptomatic calf vein thrombi, and it is still unknown if more travellers were screened if an increase in the incidence of proximal vein thrombosis would be found. Also unknown is whether thrombosis rates would be higher in at-risk patients who were excluded from the study.

The cause of the thrombi is probably venous stasis that results from prolonged sitting. It has been known since World War II that sitting can predispose individuals to thrombosis. Although the hypoxic cabin environment is often touted as a cause of thrombosis, recent data suggest that this is not the case, and, in fact, hypoxia may actually increase fibrinolysis. ${ }^{1}$

Elastic stockings are known to offer modest DVT protection in surgery patients. Stockings were effective and are an easily applied prophylactic measure, especially given the difficulties in trying to exercise in modern aircraft. It is still unknown whether patients at higher risk for thrombosis would benefit from more aggressive pharmacological prophylaxis.

Thomas G DeLoughery, MD Oregon Health Sciences University Portland, Oregon, USA

1 Grover RF, Bartsch P. Blood. In: Hornbein TF, Schoene RB, eds. High altitude: an exploration of human adaptation. New York: Marcel Dekker, 2001:493-523.

Class-I elastic compression stockings v no stockings during long-haul flights $\ddagger$

\begin{tabular}{lllll}
\hline Outcomes at 48 hours & Stockings & No stockings & RRR (95\% Cl) & NNT (CI) \\
\hline Deep venous thrombosis & $0 \%$ & $12 \%$ & $100 \%(69$ to 100$)$ & $9(6$ to 15$)$ \\
\hline & & & RRI & NNH (CI) \\
\hline Superficial thrombophlebitis & $4 \%$ & $0 \%$ & $\infty$ & 25 (13 to 629$)$ \\
\hline
\end{tabular}

Source of funding: in part, Medi UK Ltd.

For correspondence: Mr J H Scurr, Lister Hospital, Chelsea Bridge Road, London SWI W 8RH, UK. Fax +44 (0) 207259 9938. 